\title{
JUVENTUD Y TRIBUS URBANAS
}

\author{
JUAN CARLOS MOLINA*
}

PARA MEDITAR ACERCA DEL «discurso sobre lo juvenil» es necesario hacerse la pregunta: ¿quiénes fueron y quiénes son los jóvenes para las ciencias sociales?

Pablo Cottet, ${ }^{1}$ se cuestiona acerca de la manera en que se ha estudiado a la juventud. Durante los 50 y 60 las ciencias sociales enfocaron principalmente el tema del desarrollo, un desarrollo entendido conceptual y teóricamente dentro del marco de la necesidad de una industrialización, más aún, de una creciente demanda de calificación del trabajo. La educación, y principalmente, la universidad, se transforma en el eje determinante de dicho desarrollo. A raíz de esto, para las ciencias sociales, los jóvenes de la década de los 60 , fueron únicamente los jóvenes universitarios, los jóvenes trabajadores y los jóvenes universitarios y trabajadores. Las demandas sociales y políticas, tenían un sentido de acción participativo, enmarcado dentro de un contexto institucional.

Como sabemos, durante el período dictatorial chileno, en las ciencias sociales se habló más bien de los jóvenes pobladores y de los jóvenes excluidos o marginales, aquellos que protagonizaron numerosos desórdenes públicos y protestas contra el gobierno militar. De

* Sociólogo Universidad ARCIS. Actualmente es académico del Instituto Técnico Profesional AIEP y asesor de la Oficina de Asuntos Juveniles de la Municipalidad de Viña del Mar.

1 Pablo Cottet (1994): «Los cambiantes discursos sobre la juventud». Proposiciones $\mathrm{N}^{\circ} 24$. Santiago: Ediciones SUR. 
acuerdo a un estudio del Instituto Nacional de la Juventud (INJ) los jóvenes fueron el grupo social más afectado por las políticas del gobierno autoritario:

Las altas tasas de desocupación, así como las más visibles secuelas de persecución política, atropello a los derechos humanos, daño psicológico, transgresión normativa, se concentraron en este sector. ${ }^{2}$

La juventud urbano-popular durante el período dictatorial protagonizó protestas, barricadas y numerosos enfrentamientos con carabineros y fuerzas de orden. Según Weinstein:

Los jóvenes populares se apropiaron del espacio de su población marginal y desarrollaron un conjunto de acciones de desobediencia que fueron más allá de las intenciones y orientaciones de los dirigentes políticos de la oposición. ${ }^{3}$

La participación social de la juventud popular de los 80, generalmente se limitó a actividades en clubes deportivos y actividades religiosas; no existían según Oscar Corvalán, «canales sindicales, de movimientos estudiantiles u otros de participación social que le permitiese el acceso a integrarse a la sociedad». ${ }^{4}$ Las actividades de carácter religioso, según Eduardo Valenzuela, tendrían un sentido comunitario — comunidades cristianas de base $-{ }^{5}$ que posibilitaba una pacífica convivencia social.

Klaudio Duarte opina que la juventud es estudiada a partir de la aplicación de una idea de los jóvenes totalmente predeterminada. Su crítica se dirige a la tendencia de las ciencias sociales a globalizar lo juvenil, no tomando en cuenta las diferencias radicales existentes entre jóvenes campesinos, pobladores, estudiantes, etc., además de no con-

2 Instituto Nacional de la Juventud (1992): «Proyecto de construcción de una política integral de juventud: diagnóstico de la realidad juvenil de los 90». Santiago: INJ.

3 José Weinstein (1990): Jóvenes pobladores y el Estado. Santiago: CIDE, p.22.

$4 \quad$ Oscar Corvalán (1986): Educación técnica y movilidad social de los jóvenes urbano populares. Santiago: CIDE, p.18.

5 Más que un refugio, Valenzuela opina: «se trata de un movimiento expansivo que invoca la necesidad de una refundación comunitaria del mundo: el desmantelamiento de las relaciones autoritarias y la supresión de un orden social basado en el cálculo de beneficios privados». Eduardo Valenzuela (1984): La rebelión de los jóvenes. Santiago: Ediciones SUR. 
siderar el carácter dialéctico del mundo joven (ignorándolo como proceso en movimiento), sino más bien percibiéndolo a partir de etapas delimitadas e independientes. ${ }^{6}$

Es así como se procede a estigmatizar un discurso estereotipado sobre la rebeldía de los jóvenes, entendiéndola primero en el marco del cambio evolutivo biológico, y luego evaluándola — como lo hace Valenzuela - en torno al problema del orden e integración social.

«Los jóvenes de Chile, —según un estudio de Chile Sustentable-, transitan por senderos difíciles. Son estigmatizados por el discurso oficial como apáticos, anómicos y carentes de inquietudes; estereotipados como sujetos proclives a la violencia y la delincuencia, no encuentran hoy espacios confiables donde poder mostrarse». Las autoridades, por su lado, «diseñan planes y programas buscando una equidad que nunca llega, en gran medida porque los jóvenes son tratados también como meros recursos económicos, a ser domesticados para ser funcionales al modelo». ${ }^{7}$

Según Duarte, para muchos investigadores la juventud no es más que «una condición natural, sin diferencias, definida por su proceso psicobiológico, independiente de los condicionamientos históricos, económicos y culturales que la producen». ${ }^{8}$ Existiría, por lo tanto, una tendencia a naturalizar las prácticas juveniles.

Cabe señalar que son poco valoradas las prácticas juveniles que no se relacionan directamente con la economía, el trabajo y el consumo. Es que además estas prácticas suponen para muchos teóricos tan solo un período transitorio del desarrollo del pensar y actuar del sujeto; no se consideran, por lo tanto como gestoras de acciones significativas, creativas o fundacionales. Más aún, el pensamiento clásico: «la irresponsabilidad es propia de los jóvenes», ha llevado a no considerar dentro del concepto de juventud, a aquellos jóvenes obligados a asumir su realidad (responsabilizarse) por diversas razones, principalmente debido a su condición socioeconómica.

Duarte plantea la intención en las ciencias sociales de dejar fuera al joven, de desplazarlo de la historia, de negar la interacción social generada durante el propio proceso de socialización.

$6 \quad$ Klaudio Duarte (1994): Juventud popular. Santiago: LOM y Colectivo Juvenil Newence.

$7 \quad$ Proyecto Chile Sustentable, publicación año 1998.

8 Klaudio Duarte: op. cit. 
Estamos de acuerdo con Duarte en que es necesario estudiar a los jóvenes dentro de su realidad, valorando la creatividad de sus prácticas sin delimitar su accionar a partir de una visión funcional de las relaciones sociales. Como señala Pablo Cottet:

Si queremos comprender fenómenos sociales en los que los jóvenes aparecen involucrados (como víctimas, protagonistas, etc.) debemos estudiar los espacios de habla que construyen esa misma realidad social. ${ }^{9}$

Según Cottet, a partir de los 90 las ciencias sociales se enfrentan a cambios conceptuales en torno a lo juvenil; de partida, lo juvenil va a perder su sentido transitorio:

Pareciera que asistimos al fin de lo juvenil definido como el momento/lugar donde lo social era el juego por «llegar a ser alguien». Fin de lo juvenil como el juego en que cada quien debía definirse, fin de un juego que consistía en administrar la existencia para acceder al orden. Fin de una comprensión de lo juvenil, en que resolver socialmente la existencia de cada quien, confirmaba la reproducción social como resolución del orden». ${ }^{10}$

Por lo tanto la práctica juvenil se niega a ser definida; debemos entender que se instala en torno a la búsqueda, a partir de una identidad joven y abierta, basada en una incertidumbre, en una espera; por ello Cottet hablaría de la generación del suspenso.

\section{SOBRE LA JUVENTUD: ¿QUÉ SE INVESTIGA?}

Las ciencias sociales se preocupan de estudiar lo que consideran «problemas» en el ámbito juvenil, mayoritariamente causados por jóvenes que no estudian, o están desocupados y con mucho tiempo libre (el joven problema).

Se investiga: i) en torno al trabajo: el desempleo: inserción y capacitación laboral; ii) en torno a la salud: sexualidad: promiscuidad, embarazo adolescente, SIDA; iii) en torno a la educación: educación general (básica y media): deserción escolar, educación sexual (JOCAS); iv) en torno al orden y la legislación: delincuencia: violencia, drogadicción, alcoholismo, criminalidad.

9 Pablo Cottet: op. cit.

10 Pablo Cottet y otros (1997): «Jóvenes de los 90: la generación de los descuentos». Santiago: INJ. 
En este marco lo juvenil generalmente se estudia a partir de enfoques $y$ disciplinas que aplican a cada caso los siguientes conceptos claves:

Criminología: Conductas desviantes. Medidas preventivas y represivas. Discurso policial y tipologías delictivas.

Psicología social: Desviación. Autodestrucción. Marginación.

Neuropsiquiatría: Síndromes paranoides y esquizoides. Patologías mentales y relacionales.

Sociología: Grupos gregarios y líderes carismáticos. Anomia. Construcción social de la realidad. Violencia instrumental y expresiva.

Antropología: Conflicto interracial. Violencia simbólica. Intensidad relacional. Territorialidad y vínculo. Sistemas culturales: producción y transmisión.

Etología: Territorio, marcas y señales. Conflictos jerárquicos, grupos, pandillas y otras formas organizativas.

Semiótica: Construcción discursiva de la identidad. Circulación del sentido. Actuaciones y representaciones.

Comunicología: Estrategias y tácticas comunicativas, difusión y propagación de modelos, mensajes y recepción, relaciones e influencias entre individuos y grupos. Medios. ${ }^{11}$

El tiempo libre, el ocio, — generado por la deserción escolar, el desempleo, o bien por una inserción precaria en el trabajo (subempleos esporádicos)—, es el factor del mundo joven más problematizado por las ciencias sociales. Muchas veces, al igual que las políticas sociales de gobierno, las ciencias sociales entienden que los jóvenes que no pueden o no tienen nada que hacer: necesitan ser educados, capacitados, integrados, castigados, etc. Ni las políticas de gobierno ni las ciencias sociales aceptan al joven como un legítimo otro en la convivencia social si no cumple cabalmente con los roles que la sociedad le tiene previamente asignados.

De acuerdo al Proyecto Chile Sustentable:

Se supone que los jóvenes están en un proceso de formación de su personalidad y que, en consecuencia, viven el momento óptimo para la intervención moralizadora y normativa de los mayores. Una concepción como ésta se articula pronto con otra paralela, que no busca definir lo que es ser joven, sino lo que debiera ser. El proyecto oficial de sociedad en Chile lo encauza hacia las tareas de producción y consumo, y quiere transformarlo pronto en un ciudadano integrado al orden social establecido. ${ }^{12}$

11 Pérez-Oriol Costa y otros (1996): Tribus urbanas. El ansia de identidad juvenil: entre el culto a la imagen y la autoafirmación a través de la violencia. Barcelona: Paidós, p.16.

12 Proyecto Chile Sustentable: op. cit. 
Por ello, hablar del tiempo libre resulta ser bastante complejo, ya que necesariamente hay que referirse al problema de la libertad individual; la libertad de los jóvenes de decidir cuáles son y qué valor tienen sus necesidades más elementales.

Edmundo González aporta con otra definición del tiempo libre que corresponde a la adoptada por el grupo internacional de las ciencias sociales:

El tiempo libre es el conjunto de ocupaciones a las cuales el individuo se entrega con plena aceptación para descansar, divertirse, o desarrollar su formación desinteresada y su participación social voluntaria, después de ser liberado de las obligaciones profesionales, familiares y sociales. ${ }^{13}$

Norbert Elías opina de otra forma con respecto al tiempo libre; según señala, es toda actividad sin fines de lucro, actividad que no siempre se distribuye en actividades de ocio. Por ello es inadecuada la polarización ocio-trabajo, pues no todo el tiempo libre se destina a actividades recreativas, de ocio. El trabajo ocupacional asalariado entendido como la subordinación de los sentimientos personales - una racionalización - también cubre en nuestras sociedades las actividades del tiempo libre. El grado de coerción, de contro1 social se da en distintos niveles, anulando toda excitación y emoción. Según Elías la familia puede ser potencialmente la gestora de esta coerción, a través de la restricción de las emociones.

Elías plantea el espacio deportivo como espacio de despliegue del ocio, aquel que permite un escape de la rutina, que resulta ser muchas veces coercitiva. En su «Borrador preliminar para una tipología del espectro del tiempo libre» destaca las siguientes actividades en tiempo libre: i) trabajo privado y administración familiar; ii) descanso; iii) satisfacción de las necesidades biológicas; iv) sociabilidad; v) actividades miméticas o de juego.

Las actividades miméticas o de juego «son actividades de tiempo libre con características de ocio, participe uno en ellas como actor o como espectador». 14

El deporte tiene para Elías una implicancia dialéctica en lo social, al interior de las distintas esferas sociales: económica, social,

13 Edmundo González (1996): «Alternativas del ocio». Documento de Trabajo INJ. Santiago: INJ.

14 Elías Norbert y Eric Dunning (1992): Deporte y ocio en el proceso de la civilización. México: FCE. 
cultural, emocional. Elías busca ir más allá, generando las bases conceptuales para una «teoría sociológica de las emociones» y con especial atención a las conductas de violencia en los recintos deportivos: los hooligans. Elías revaloriza al deporte:

El deporte es catalogado como una actividad trivial, recreativa, orientada hacia el placer, que emplea el cuerpo más que la mente y que carece de valor económico. ${ }^{15}$

Junto a las actividades mimético deportivas (las pichangas), las actividades lúdico-grupales que se dan en la calle son las principales actividades realizadas durante el tiempo libre del joven popular. Entre las actividades miméticas de tipo grupal la más común es el consumo de alcohol.

Las políticas que abordan al mundo juvenil buscan ejercer control sobre el joven problema, efectúan estudios y trabajan en torno a las variables: pobreza, alcoholismo y delincuencia.

Sin embargo, la televisión sigue siendo el principal recurso de distracción tanto para jóvenes, niños y adultos; por ello este aparato comunicacional trabaja en torno a la comercialización del ocio, transformándolo en un elemento fundamentalmente más importante para la economía — neoliberal— que para la cultura.

Un estudio realizado en Santiago por Adimark (1995), con una muestra de 631 personas mayores de 15 años, reveló que un $45,4 \%$ dedica su tiempo libre a ver televisión, sólo un 34\% se dedica al deporte y un $26 \%$ a escuchar música. ${ }^{16}$

Veamos los planteamientos efectuados por un estudio sobre la Comercialización de los ocios, ${ }^{17}$ realizado en Suecia:

- el comercialismo neutraliza las necesidades fundamentales al mismo tiempo que simula satisfacerlas;

- el comercialismo crea una visión deformada de la humanidad y trabaja en pro de un humanismo egocéntrico;

- el comercialismo cultiva el mito de la eterna juventud;

- el comercialismo refuerza la alienación y utiliza la inseguridad popular;

15 Ibid, p.27.

16 Encuesta Adimark 1995. Documento de Trabajo INJ. Sección Información y Documentación.

17 La comercialización de los ocios, Suecia, Documento de Trabajo INJ. Santiago, 1996. 
el comercialismo crea necesidades artificiales mediante la publicidad y los estudios de mercado.

La falta de contenido social y el vacío comunicacional que plantea la comercialización de la libertad individual, particularmente de los jóvenes - fácilmente influenciados por este culto a la imagencrea un ambiente de frialdad sociocultural que congela cualquier acción de tipo asociativo.

Sin embargo, diversos trabajos realizados sobre pandillas y tribus urbanas, concluyen que ante el aislamiento individualista propio de la sociedad competitiva, al interior de todo joven se declara una instintiva y explosiva reacción, provocada particularmente por la necesidad del contacto humano: la juventud, a pesar de la televisión, sigue encontrándose, reuniéndose en torno a plazas, botillerías, pasajes, el estadio. Las discoteques, bares, pubs y malls también son centros de reunión, pero como están principalmente enfocados al consumo, tienden a segregar a los jóvenes de acuerdo a su estatus socioeconómico.

Como sabemos, el joven espera ansioso el fin de semana; para él lo cotidiano vendría a ser un tiempo muerto, un tiempo de espera. Según Costa, Pérez y Tropea:

\begin{abstract}
$\mathrm{Al}$ estar muy poco o nada «enganchados» con la sociedad dominante, o sea, la sociedad de la productividad urbana (salvo el hecho básico de ser, en cierto modo y a pesar suyo, «hijos» de esa sociedad), ese tiempo se convierte en algo poco relevante y ordinario. Por eso los miembros de las tribus necesitan imaginar algo significativo, algo que supere la anomia que genera el anonimato. ${ }^{18}$
\end{abstract}

El fin de semana le da un sentido a lo cotidiano, para el joven equivale a un tiempo para vivir intensamente, al tiempo de actuación en que se renueva, imaginativa y simbióticamente, la identidad individual y grupal: «un tiempo del nosotros» ${ }^{19}$ como juventud. Para Daniel Contreras el carrete es un elemento central en la identidad juvenil:

La dimensión «construcción de la identidad» entre los jóvenes está hoy más cerca de lo ritual que de lo social-contractual [...] más cerca de la «presencia» que del «logos». Aquí es donde ubicamos el carrete, la fiesta juvenil, el

\footnotetext{
18 Pérez-Oriol Costa y otros: op. cit., p.135.

19 Ibid, p.137.
} 
encuentro transversal de personas con biografías distintas. ${ }^{20}$

El carrete es el espacio que convoca a los jóvenes a ser lo que desean ser, es el lugar ritual en el cual se transgrede, se plantea un «quiebre simbólico de la propuesta de vida entre tercios (tiempo de trabajo, tiempo de recreación y tiempo de descanso)». ${ }^{21}$

Pero no sólo el tiempo libre, también la desconfianza y el desinterés en la política y en las instituciones, son elementos que han preocupado a las políticas y ciencias que tratan lo juvenil.

La indiferencia manifestada por parte de la clase dominante - particularmente político-empresarial — en torno a la opinión de los jóvenes populares sobre las decisiones: políticas (arresto de Pinochet, senadores designados), culturales (censura, espacios de expresión y financiamiento) y económicas (privatización de los servicios, salario mínimo), al parecer ha generado en ellos una enorme desconfianza que se manifiesta material y simbólicamente en las urnas — tanto en la no inscripción electoral como en votos nulos o blancos- y también en la calle — protestas universitarias, desmanes causados por barras bravas, enfrentamiento entre pandillas, etc.-.

Para Rafael Gumucio, hablar de desinterés de los jóvenes en la política es insultar su inteligencia y su capacidad de criticar y de discernir en torno al quehacer político. Gumucio sostiene:

Si detestan a los políticos es por razones absolutamente políticas, porque los políticos de hoy les han hecho la guerra. Les han quitado películas del cine, programas de televisión de la pantalla, se han reído de sus votos, han mandado a la policía encima, han revisado sus camas, y les han cobrado carísimo una pésima educación. ${ }^{22}$

No está de más decir que una encuesta realizada por el INJUV en 1997, demostró que de un total de 3.446 jóvenes de 15 a 29 años, el $80.6 \%$ no tiene interés en los partidos políticos, y un 78\% opinó que los políticos no se preocupan por los jóvenes:

La experiencia de los 90 contrasta con la visión de la década pasada, por cuanto muestra un sistema que no alcanza legitimidad suficiente. ${ }^{23}$

20 Daniel Contreras (1996): «Sujeto juvenil y espacios rituales de identidad: el caso del carrete». Proposiciones N²7. Santiago: Ediciones SUR, p.43.

$\begin{array}{ll}21 & \text { Ibid, p.44. } \\ 22 & \text { Rafael Gumucio (1999): «¿Por qué creer en los políticos?: Un mutuo des- }\end{array}$ precio». Revista Rocinante No5, Santiago, p.7.

23 Encuesta INJUV 1997. Sección Información y Documentación. 
Con respecto a la «legitimidad» de la clase política, ésta se perfila a partir de una mirada «desde abajo», según Gabriel Salazar «la ciudadanía también tiene ojos. Y no uno, sino millones. Y no centrales, sino circundantes». El concepto «clase política» se constituye a partir de su reflejo en el ojo-horizonte del ciudadano «ojo que no la ve como una fuerza jurídica abstracta, sino como un conjunto de personas que revisten representación, riqueza, o poder». ${ }^{24}$

Dicen que la juventud no tiene interés en la política o en inscribirse en los registros electorales. Pero qué interés puedo tener yo cuando con lo que lucharon mis papás por la democracia, democracia entre comillas porque la democracia no nos ha demostrado a los jóvenes que luchamos que ha cambiado algo [...] los ricos cada vez más ricos, los pobres cada vez más pobres (Rodilla). ${ }^{25}$

La violencia, ${ }^{26}$ es el tema que en la actualidad preocupa a los diversos sectores (políticos, administrativos, represivos) de la sociedad, y en particular a las ciencias sociales.

A luz de dos incidentes claves: un carabinero quemado por una bomba molotov a las afueras del ARCIS durante una protesta la primera semana de septiembre y la muerte de una garrera por hinchas de la Universidad de Chile frente al Estadio Monumental, Televisión Nacional de Chile (TVN) realiza un reportaje a fondo a los encapuchados universitarios, y a los miembros de la Garra Blanca:

En el Estadio, la Garra Blanca, nosotros controlamos a nuestra gente, pero un prefecto o un mayor ¿controla a los cabos?: no, porque ellos son los que más tienen bronca con la juventud (Androide). ${ }^{27}$

Las manifestaciones de violencia son justificadas tanto para los garreros, como para los encapuchados: la pobreza, la marginalidad, la injusticia producto de un sistema neoliberal que los asfixia. Ambos grupos deben enfrentarse a la represión por parte de la sociedad política y la fuerza pública, y en algunos casos a la justicia militar.

El gobierno no le cree a nadie en Chile. Porque protestan los mapuches, en-

24 Gabriel Salazar y Julio Pinto (1999): Historia contemporánea de Chile I. Santiago: LOM, pp.69-70.

25 Informe Especial: «Violencia juvenil», TVN, 10 de septiembre de 1999.

26 El tema de la violencia lo desarrollaremos con mayor detención a lo largo de nuestra investigación.

27 Informe Especial: loc. cit. 
tran las fuerzas represivas, protestan los estudiantes, entran las fuerzas represivas. El aparato es represivo en Chile (Víper). ${ }^{28}$

TRIBUS URBANO-POPULARES: ¿CÓMO VIVEN LOS JÓVENES POPULARES?

El joven poblacional, o como lo llama Weinstein: el joven urbano-popular, se enfrenta diariamente al desempleo o al subempleo. Su vida gira en torno a la inactividad: no estudia ni trabaja, y generalmente, tampoco ayuda en el hogar. Con respecto a la juventud de los 80, señala: «estos jóvenes han sido 'clientes' importantes de los improductivos y mal remunerados planes de empleo impulsados por el Estado»: ${ }^{29}$ el Programa de Empleo Mínimo (PEM), y el (Programa de Empleo para los Jefes de Hogar (POJH), única iniciativa del Estado frente al fuerte desempleo de esos años. No es extraño entonces que Weinstein hable de la juventud como la edad de la espera.

Ésta fue una generación que durante un largo período fue despreciada como potencial humano, generándole graves daños sicosociales muy difíciles de reparar a través de políticas de gobierno (capacitación laboral, centros de rehabilitación, etc.). Tanto en los 80 como en la actualidad, el joven popular-urbano enfrenta una marginalidad tanto en el empleo como en la vivienda (muchos viven en calidad de allegados), en la salud (drogadicción, alcoholismo) y en la educación. Sin embargo, tristemente, es está marginalidad la que ha posibilitado el «reconocimiento» de la juventud por las ciencias sociales y los programas de gobierno.

Claro que este «reconocimiento» parte de una premisa éticomoral: los jóvenes están en un proceso de formación y es el momento de adecuarlos a la normativa social vigente. Esta concepción está enmarcada en un debiera ser que niega la identidad propia de cada joven. Tanto las ciencias sociales como los programas de gobierno encauzan al joven «hacia las tareas de producción y consumo, y quieren transformarlo pronto en un ciudadano integrado al orden social establecido». 30

Humberto Abarca realiza un análisis crítico del futuro (programado) del joven popular:

\footnotetext{
28 Ibid.

29 José Weinstein (1989): «Problemas de la juventud: desafíos de la sociedad chilena». Documentos de Discusión. Santiago: CIDE.

30 Proyecto Chile Sustentable: op. cit.
} 
La ideología del ascenso social se inculca como mentalidad de generación a generación, expresada en un discurso que promueve dos actitudes ante el futuro: devoción a la promesa y atrevimiento para cumplirla; de conjunto representan una barrera que antepone el dicho «no tenemos oportunidades». Así la recepción de la promesa de futuro se transforma en un acto de fe colectiva. ${ }^{31}$

Sabemos lo que sucede con aquellos jóvenes que desconocen dicha promesa. Los denominados aplanadores de calles, los cabros de la esquina, comienzan a ser un problema en barrios y comunas. Pasar el día en la calle, sin hacer nada, jugando video juegos, o bien consumiendo alcohol, es visto por la comunidad como un acto de rebeldía, un factor que llama a la delincuencia.

En todas las grandes ciudades la situación de los niños y jóvenes que han optado por la calle va en aumento [...] El espacio urbano, símbolo capitalista de expansión y desarrollo, se convierte en un lugar de vida para estos niños y jóvenes. Las principales razones invocadas por los distintos autores para explicar el fenómeno son: la marginalidad urbana acaecida desde el industrialismo de los 60, la pobreza como una cultura productora de dificultades sociales; la familia en crisis; la economía globalizadora; el individualismo creciente y la falta de solidaridad. ${ }^{32}$

En las calles, particularmente, el fenómeno del licor-embriaguez posee diversas lecturas, políticas y sociales enfocadas en torno a la población juvenil. Por su parte, las autoridades de gobierno se preocupan por la temprana edad en que los jóvenes comienzan a consumir alcohol.

Todos los fines de semana me toca sacar a niños y niñas de los jardines, desde doce años para arriba, que se esconden a tomar vino en caja y pisco. El problema es que la falta de experiencia les hace emborracharse hasta el límite de quedar botados. Hace una semana una niña de 13 años se intoxicó, tuvimos que llamar una ambulancia para que se la llevara (Nochero discoteque capitalina). ${ }^{33}$

Se desprende del diagnóstico juventud-alcohol, un tipo específico de dispositivo discursivo que moviliza y explicita —a través de la

31 Humberto Abarca (1996): «Viaje al centro de la jungla: el discurso juvenil sobre el futuro». Proposiciones No27. Santiago: Ediciones SUR, p.13.

32 María Emilia Tijoux (1998) (coordinadora): «Jóvenes de la calle: realidad de la Región Metropolitana». Santiago: Centro de Investigaciones Sociales, Universidad ARCIS, pp.256-257.

33 La Tercera, Reportajes, Santiago, 31 de febrero de 1995. 
opinión pública - fuerzas policiales e instituciones asistenciales: un artefacto de control activado en los 80 por el régimen militar. Esta reconstrucción arbitraria del sujeto juvenil popular por parte de la institucionalidad operante, movilizó discursos morales, médicos, psicológicos y sociales basados en una juventud amoral, enferma e inadaptada.

La política que abordaba el mundo juvenil popular durante el régimen dictatorial, tenía como objetivo ejercer control sobre el joven problema, articulado en torno a las variables: pobreza, alcoholismo y delincuencia.

Con estas instalaciones discursivas, los aún operantes artefactos de poder se desarrollan de forma legítima sobre los cuerpos de los infames. Al igual que con las brujas, los leprosos y los locos en siglos anteriores; ahora, los chascones, los trashers, los drogadictos, los encapuchados y las barras bravas son los nuevos infames que entran en el mercado de la ortopedia social.

\section{LA VIOLENCIA EN LA URBE POPULAR}

La juventud urbano-popular experimenta un acostumbramiento a la violencia, producto de una socialización afectada directa o indirectamente por hechos violentos: autoritarismo por parte del gobierno y los mecanismos de control implantados por éste, rechazo y desconfianza dentro del mundo adulto, violencia verbal y/o física por parte de sus pares.

Resultan lógicas las conductas violentas en un contexto donde los jóvenes populares son socializados y marginados violentamente. Sin embargo, la violencia en el mundo del joven no puede ser explicada únicamente a partir de las variables pobreza y marginalidad (perspectiva instalada durante el gobierno militar). Más que un mero acto de resentimiento, la violencia dentro del ámbito juvenil está legitimada, según Weinstein, como una forma de resolución de conflictos y como fórmula para adquirir estatus y privilegios.

No parece suficiente, sin embargo, señalar que el joven busca la resolución del conflicto a partir de la violencia, pues ésta se manifiesta comúnmente como una «puesta en juego» de conflictos, descontento, pasiones que no terminan en la propia violencia como único fin en sí misma, sino como medio de expresión. Entran en juego varios factores, como son la territorialidad, las rivalidades, la competencia, el mérito frente a los otros, etc. 
De acuerdo a lo señalado en Tribus urbanas, la violencia corporal, la agresividad física, es detonada por una necesidad de contacto, «el gusto por una violencia que proporciona —en una perspectiva de lo inmediato y de lo a racional— la sensación del calor, la pasión y la adrenalina». Por otro lado, la violencia contra la propiedad corresponde a algo distinto, y absolutamente simbólico, éste es un «sacrificio de objetos pertenecientes a lo público en una sociedad que celebra hasta la saciedad el culto al objeto». ${ }^{34}$

Muchos jóvenes, no necesariamente pandilleros, buscan a tientas un escape a la marginalidad a través de actividades extraordinarias y/o relaciones comunitarias como son: la música (hip hop, punk, trash, hardcore), el deporte (clubes deportivos amateur, barras), la religión (iglesias protestantes, las misiones), la política (militantes, encapuchados), etc. El problema es que, como señala Emilia Tijoux: «tanto el comunitarismo como el alternativismo no tienen hoy cabida en los esquemas teóricos de la modernidad liberal, tal como ésta se define y administra hoy en Chile». ${ }^{35}$ Estamos conscientes de que las alternativas de los jóvenes urbano populares dentro del sistema neoliberal son el ser funcionales al modelo económico imperante o ser marginales y perseguidos por la sociedad.

Como hemos señalado anteriormente, las políticas y acciones llevadas a cabo por el gobierno militar en torno al mundo juvenil oscilaron entre la «mitología» y el «estigma», haciendo «justificables» los actos de represión ante la opinión pública. El accionar político frente a este grupo será desde la caridad-asistencial o desde la vigilancia, naturalizando la instalación discursiva del joven problema.

La instalación discursiva del joven promesa la encontraremos nuevamente en períodos coyunturales; en este caso fue el plebiscito de 1988, donde, «en principio» se le permite al joven participar del espacio político. Ahora sabemos que la llamada participación de la juventud en la política no es tal, ya que, tan sólo para plantear sus demandas los jóvenes han tenido que luchar en las calles y en las universidades.

\section{TRIBUS URBANAS}

El joven poblacional, el joven «marginado», va a tener siempre una enorme energía expresiva; el «no ser escuchado» no frustrará

34 Pérez-Oriol Costa y otros: op. cit., pp.39-47.

35 María Emilia Tijoux (1994): «Juventud popular en peligro de vida». Proposiciones $\mathrm{N}^{\circ} 24$. Santiago: Ediciones SUR. 
sus inquietudes de participación. El barrista, por ejemplo, siempre va a canalizar su energía expresiva en el Estadio, las gradas y en las calles y su expresión será siempre una acción social y política relevante.

\begin{abstract}
Las pandillas juveniles son constructoras de espacio, del espacio de la esquina, del rincón bajo la escalera del block. A su manera construyen espacio desde ese rincón escondido, en las sombras, en la esquina, en las barras bravas, lo que ustedes quieran, eso es tejido social, eso es red social, eso es construcción de identidad, eso es construcción de lenguaje. El «no estar ni ahí» es una creación lingüística maravillosa, hay ahí una cultura que circula oralmente, para eso conversan. ${ }^{36}$
\end{abstract}

Podemos observar energía expresiva en diversos grupos juveniles populares urbanos como los raperos, punkies y trashers. Estos grupos muchas veces excluidos, podrían ser vistos por las ciencias sociales como jóvenes víctimas, apelando a la clásica visión paternalista de Estado. Por otro lado, estos jóvenes se arriesgan también a ser atrapados por la administración del Estado, y sus prácticas o expresiones no serán comprendidas en su real dimensión, siendo manipuladas y administradas por programas de gobierno (rehabilitación, capacitación laboral, etc.) que parten de una conceptualización del mundo juvenil popular que sólo los estigmatiza. Además, como ya señalábamos, todo esto está determinado por un interés social-funcional del sistema político-económico.

Cuando los jóvenes no tienen a su alcance los medios para expresarse y relacionarse con su entorno como desean, desarrollan una manera auténtica, un sentido comunitario de historicidad. En su búsqueda muchos integran agrupaciones que en las que se manifiestan fuertes redes solidarias a través de diversas actividades tanto lúdicosociales como político-culturales.

Un espacio físico donde expresarse es lo que primero buscan, ya que tanto la sensación de pertenencia física (a un territorio delimitado) como simbólica (la proximidad a una comunidad afectiva) les permite identificarse y reconocerse como individuos.

De acuerdo a lo señalado en el Proyecto Chile Sustentable:

La participación juvenil en organizaciones se vincula al uso del tiempo libre, es decir, tienen lugar fuera de las actividades centrales de estudio y trabajo. En este sentido, la falta de espacios de acción cultural o recreacional

36 Daniel Contreras (1996) (compilador): Jóvenes de los 90. Santiago: Vicaría Pastoral Social. Intervención de Gabriel Salazar, p.26. 
provoca que los jóvenes pobladores hagan un uso importante de los lugares públicos como calles, plazas y parques. ${ }^{37}$

Se dice en Tribus urbanas, que el espacio ocupado por la tribu le permite la oposición simbólica de un «fuera» y de un «dentro» que ayuda a la (re)contrucción de una identidad, creando dos identidades: la propia y la ajena. Las agrupaciones juveniles o pandillas se apropian de distintos espacios urbanos, espacios que, simbólicamente responden a las siguientes funciones expresivas:

i) De pertenencia: Los lugares a los que pertenezco y que por eso me pertenecen. Puntos de referencia territorial para todos los miembros de una tribu, esos lugares especiales suscitan un especial sentimiento de posesión pero también un ámbito seguro en el que la tribu ejerce un control más directo sobre los acontecimientos. Un bar punk es un ejemplo de ese espacio de pertenencia, así como un estadio o una parte del mismo lo es para un hooligan.

ii) De representación: Los lugares en que me represento (a mí mismo y a los demás) como miembro de una tribu, similar a todos sus miembros y distinto a todos los demás. Se trata del lugar en que se exhibe el aspecto más superficial, espectacular de la identidad, a través de la máscara. Aquél en que se luce el uniforme más completo y por ello más representativo [...].

iii) De actuación: Los lugares en donde se persiguen los objetivos lúdicos y/o existenciales del grupo. Son espacios que pueden coincidir parcialmente con los dos anteriores, ya que el territorio de la actuación puede ser también el de representación de la identidad». ${ }^{38}$

Todos aquellos espacios ganados por la tribu serán de alguna forma defendidos. Los enfrentamientos entre tribus se agudizan particularmente en las ciudades densamente habitadas y a menudo pueden traducirse en acciones criminales con carácter delictual.

Es común que la seguridad que se manifieste a través del apretado tejido de relaciones afectivas al interior de un grupo posibilite al joven participar en acciones violentas o delictivas; para ello el sentirse un sujeto anónimo es crucial, siendo un anonimato que no entra en contradicción con su identidad, todo lo contrario, un anonimato que le permite fortalecerla. Según Weinstein, al interior de una pandilla: «se disminuye lo que lo separa de los demás y se acentúa lo que tiene en común»;39 este sentir en vez de aislar al joven como individuo, lo 
compromete, lo encauza, lo contagia y lo convierte en cómplice del accionar de sus compañeros.

Yo sabía que él participaba desde hace dos años en esta pandilla rapera, y sé que siempre se juntaban a jugar, a bailar y a ir a fiestas como todos los niños de su edad (Madre de joven rapero detenido en una riña). ${ }^{40}$

La agresividad y la violencia que ha caracterizado a muchas pandillas no se puede explicar por fuera de la realidad económica y política chilena. Al estar insertos en un mundo competitivo, - un mundo en que se espera que su accionar sea económicamente funcional al sistema neoliberal-, y sin embargo, no tener en sus manos oportunidades que le permitan formar parte, no es extraño que el joven poblacional se aísle y le guarde rencor al sistema económico y político que le dio la espalda.

En las tribus urbano populares — piños, agrupaciones, pandillas-, la violencia tiene un carácter simbólico: destruir o atacar todo aquello que tiene un carácter «institucional», aquello que es «ajeno», lo que ha sido «impuesto»; esto incluye no sólo la propiedad pública y privada, sino también los valores ético-morales impuestos por la sociedad. Junto a esto, la violencia es gatillada por una necesidad de contacto. Los jóvenes que optan por manifestarse de manera violenta, particularmente en forma grupal, no lo hacen sólo en plan de ser vistos - lo cual no deja de ser importante para ellos-, sino en busca de contacto físico, muchas veces porque no lo encuentran en otro ámbito que no sea ése:

Las tribus son un ámbito de contacto físico, una oportunidad para la cercanía de los cuerpos y de los sentidos, una ocasión para la evasión de un mundo demasiado frío y tecnologizado que ha hecho de la distancia y el aislamiento su naturaleza propia. ${ }^{41}$

Debemos comprender también que toda agresión física o hecho violento - tanto peleas como destrozos - , permite al joven agresor ser parte protagonista de un hecho real y definitorio. Consciente de no estar en una sala de video juegos, el joven experimenta el miedo, el dolor, el odio, la adrenalina... es quien participa en el escape o en la persecución, es el agresor, es el agredido... La búsqueda de esta

40 Las Ultimas Noticias, Reportaje «Un rap triste», Santiago, 27 de abril de 1996.

41 Pérez-Oriol Costa y otros: op. cit., pp.13. 
peligrosa experiencia no puede entenderse sin tomar en cuenta que los espacios socialmente dados para que un joven poblador pueda ser protagonista en nuestra sociedad son extremadamente limitados.

La tribu no sólo devuelve el protagonismo al joven popular, al mismo tiempo le ofrece la protección que necesita — dado que su papel protagónico no es admitivo por el resto de la sociedad-.

Costa, Pérez y Tropea nos explican el contexto simbólicosocial que envuelve a las tribus, contexto que determina su relevancia y significado tanto para los jóvenes que las componen como para la sociedad que les da cobijo.

i) Una tribu urbana se constituye como un conjunto de reglas específicas (diferenciadoras) a las cuales el joven decide confiar su imagen parcial o global, con diferentes niveles de implicación personal.

ii) Una tribu funciona casi como una pequeña mitología en donde sus miembros pueden construir con relativa claridad una imagen, un esquema de actitudes y/o comportamientos gracias a los cuales salir del anonimato con un sentido de identidad rearmado y reforzado.

iii) En una tribu tienen lugar juegos de representaciones que le están vedados a un individuo «normal». Cuantitativamente pertenecer a una tribu es una opción minoritaria en la realidad urbana, pero se hace llamativa, porque es literalmente excesiva, ya que quiere, programáticamente, excederse, superar las limitaciones, es decir, las reglas de la sociedad dominante y uniformadora.

iv) Mediante la «tribalización» se reafirma la contradictoria operación de una identidad que quiere escapar a la uniformidad y no duda en vestir un «uniforme». Se trata, por lo visto, de «impertinentes» símbolos de pertenencia, un juego entre máscaras y esencias.

v) Todas las tribus urbanas inventariadas constituyen un factor potencial de desorden y agitación social, ya que su propio acto de nacimiento representa simbólicamente «desenterrar el hacha de guerra» contra la sociedad adulta de la que, de alguna forma, no se quiere formar parte.

vi) El «look» más extremado y menos convencional revela una actitud (y una necesidad) autoexpresiva más intensa de lo habitual, y en consecuencia también más activa, pudiendo manifestarse de forma agresiva y violenta.

vii) La relación de pertenencia del individuo al grupo es intensa, globalizadora y aporta un sentido existencial. Todas sus maniobras y actuaciones parecen estar dirigidas y justificadas en función de esa pertenencia. Asistimos entonces a un evidente proceso de desresponsabilización personal de las acciones [...].

viii) Cuando se intenta aclarar en qué canales y con qué modalidades se expresan esas actitudes vitalistas y agresivas, resulta evidente que música y espectáculo deportivo constituyen los canales y las fuentes de inspiración más frecuentes. Seguramente por su potencial de agregación masiva y de intensidad emocional. 
ix) Sintomáticamente las actitudes más violentas se acompañan de una «imagen de marca» fácil de reconocer, un uniforme ceremonial, una especie de instrumento simbólico para quien quiere distinguirse por sus actos y su atuendo. A diferencia de las pandillas juveniles tradicionales, en donde el hecho delictivo —o la gamberrada - tendía a ocultarse, en esas tribus la violencia no se disimula, al contrario, se manifiesta y se muestra con orgullo, satisfacción y como sistema de provocación [...]. ${ }^{42}$

Estos investigadores destacan la importancia que tiene el contacto físico para los jóvenes tribales; como hemos señalado, compartir un espacio físico en el cual el roce resulte inevitable es algo que ellos buscarán a menudo. Las discoteques, los bares, el estadio, suelen ser los lugares preferidos por las tribus urbanas.

En el estadio las barras bravas (hooligans-skins) la fisicidad se expresará a través de una agresión simulada:

Empujones, puñetazos y posturas de artes marciales [...] comportamiento típico de la adolescencia que alcanza el paroxismo [...] cuando se celebra un gol del equipo propio. Los empujones y los contactos aumentan entonces en cantidad e intensidad, en medio de una explosión de alegría y emoción que se manifiesta como «festividad incontrolada».43

Doris Cooper considera que al contrario de lo que suele creerse, la pandilla ayuda al joven a insertarse en un núcleo. Las pandillas más violentas, señala, son aquellas con mayor participación, por lo tanto las que se forman en los barrios urbano populares:

Hay una gran diferencia con las clases altas, donde la pertenencia a pandillas es parte de un proceso de transición que vive la juventud. En las poblaciones los jóvenes ingresan a las pandillas en una edad inferior y tienen un proceso de inserción más largo. Se van dando cuenta de que la estructura de oportunidades está cerrada para ellos, por lo que no tendrán acceso a una buena educación. Saben, por lo tanto, que no lograrán roles profesionales con buena remuneración económica, y que su destino, probablemente será vender en las micros o ferias libres. ${ }^{44}$

Muchas veces, en vez de integrar pandillas los jóvenes se suman al mundo del hampa, o bien, optan por integrarse a iglesias evangélicas, satisfaciendo de otra forma su necesidad de crear vínculos

42 Pérez-Oriol Costa y otros: op. cit., pp.91-92.

43 Ibid, p.174

44 Doris Cooper: «En los jóvenes, la frustración se ha incrementado». La Nación, Santiago, 15 de marzo de 1999. 
societales. De acuerdo a su análisis, en la vida del joven popular (no siempre pandillero) se cruzan las variables: i) pobreza y marginalidad; ii) frustración ante un futuro incierto; y, iii) falta de lazos afectivos familiares.

La constante es sin duda, la búsqueda de pertenencia. De acuerdo a la tesis desarrollada por Costa, Pérez y Tropea, frente a la incertidumbre y al vacío comunicacional con que la sociedad desacoge al joven (popular), el fenómeno de las tribus urbanas se plantea:

Como una respuesta social y simbólica, frente a la excesiva racionalidad burocrática de la vida actual, el aislamiento individualista a que los someten las grandes ciudades, y a la frialdad de una sociedad extremadamente competitiva. ${ }^{45}$

Es tentativo concluir que aquello que el joven poblacional encuentra en este tipo de agrupaciones, de ninguna forma podría encontrarlo individualmente, especialmente en una sociedad consumista, que diariamente rinde culto a la imagen, dejando a un lado lo vivencial, lo propio del contacto humano. De esta manera, la tribu se plantea para el joven como "potencia agregadora frente a un poder que disgrega». 46

VIÑA DEL MAR, JULIO DEL 2000

45 Pérez-Oriol Costa y otros: op. cit., pp.11.

46 Ibid, p.14. 